Revue d'histoire de l'Amérique française

RAS REVUE D.HISTOIRE DE L'AMÉRIQUE FRANÇAISE

\title{
Recherches amérindiennes au Québec et la présumée disparition des Atikamekw et des Montagnais
}

\section{Pierre Trudel}

Volume 54, numéro 3, hiver 2001

URI : https://id.erudit.org/iderudit/005625ar

DOI : https://doi.org/10.7202/005625ar

Aller au sommaire du numéro

\section{Éditeur(s)}

Institut d'histoire de l'Amérique française

\section{ISSN}

0035-2357 (imprimé)

1492-1383 (numérique)

Découvrir la revue

\section{Citer ce document}

Trudel, P. (2001). Recherches amérindiennes au Québec et la présumée disparition des Atikamekw et des Montagnais. Revue d'histoire de l'Amérique française, 54(3), 449-451. https://doi.org/10.7202/005625ar d'utilisation que vous pouvez consulter en ligne. 


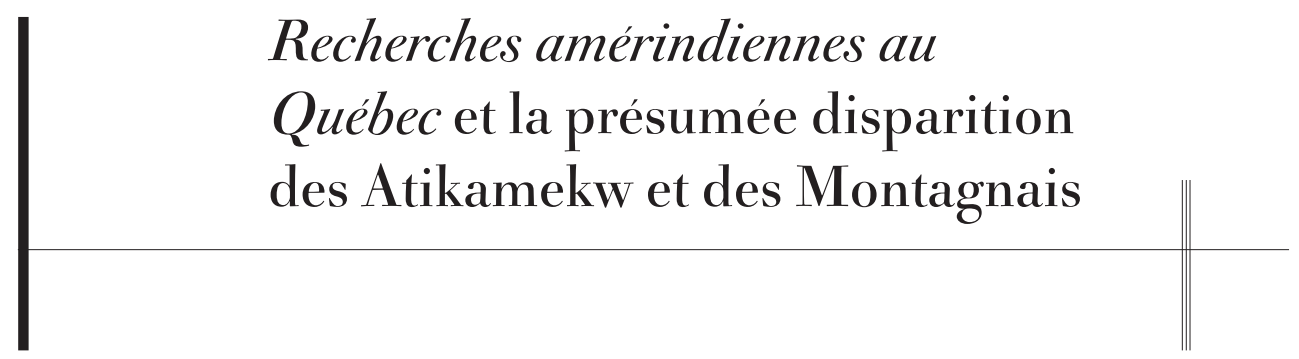

PIERRE TRUDEL

Ans SON TEXTE Les pièges de la judiciarisation de l'histoire autochtone ${ }^{1}$, Alain Beaulieu critique injustement la revue Recherches amérindiennes au Québec et ne saisit pas très bien le sens d'une de mes chroniques sous la rubrique Actualités. Rappelons brièvement les faits. Pendant deux jours, Radio-Canada reprit une nouvelle télévisée du reporter Paul Toutant affirmant que des études scientifiques démontraient que les Atikamekw et les Montagnais avaient disparu et avaient été remplacés par d'autres Autochtones qui, aujourd'hui, revendiquent à leur place des droits ancestraux. Et le gouvernement s'apprêtait à signer une entente avec eux, entente qui allait nous coûter 350 millions de dollars! Plutôt qu'être neutres et favoriser le débat en envisageant l'hypothèse de la disparition d'une nation autochtone, $R A Q$ et moi-même aurions milité en faveur d'une cause, défendant aveuglément les Autochtones.

C'est en tout cas l'impression générale qui se dégage de la manière dont la revue Recherches amérindiennes au Québec, par l'entremise de Pierre Trudel, a présenté le débat soulevé par le reportage de Radio-Canada. Le titre donnait déjà le ton : "Des Québécois menacés de disparaître font disparaître des Atikamekw et des Montagnais...» On ne pouvait être plus clair sur le sort qui 
attendait ceux qui chercheraient à démontrer qu'une nation autochtone avait été décimée après le contact avec les Européens ${ }^{2}$.

Commençons par défendre $R A Q$. Timidement, dans une note de bas de page, Alain Beaulieu informe le lecteur de la $R H A F$ que $R A Q$ a invité les historiens Maurice Ratelle et Russel Bouchard à répliquer à deux textes d'anthropologues parus dans La Presse et Le Soleil dénonçant l'interprétation abusive du reporter Paul Toutant. Ce qui n'est pas juste pour $R A Q$, c'est qu'Alain Beaulieu n'informe pas les lecteurs de la $R H A F$ que $R A Q$ a publié une réplique de Russel Bouchard ${ }^{3}$ démontrant ainsi le contraire de ce qu'il avance. Malgré le fait que Bouchard ne réponde en rien aux critiques de Charest et Clermont, $R A Q$ a publié son texte par souci de laisser place au débat et de respecter toutes les opinions. (Pour bien saisir l'importance et le caractère scientifique des questions soulevées par Clermont et Charest, j'invite le lecteur de la RHAF à lire la note de la direction publiée à la suite de la réplique de Russel Bouchard.) On comprendra que $R A Q$ a été très généreuse d'avoir publié un texte qui ne répondait en rien à au moins six arguments nuançant ou contredisant la thèse de la disparition des Atikamekw et des Montagnais. RAQ ne pouvait pas aller plus loin pour favoriser le débat! Et sans doute qu'Alain Beaulieu n’a pas lu la réplique de Bouchard avant d'accuser RAQ de partialité.

$R A Q$ a donc réédité deux textes des anthropologues Clermont et Charest que j'ai présentés dans la chronique «incriminée " par Alain Beaulieu. Quant à l'insinuation selon laquelle, au moyen d'un titre percutant, j'aurais intimidé des historiens, n'encourageant pas le débat ou l'objectivité en science, permettez-moi de citer un court extrait de cette chronique Actualités qui rend compte clairement de son orientation générale. «... nous désirons contribuer, bien modestement, à équilibrer l'information sur les revendications autochtones. En effet, le nombre de gens qui ont lu les textes de Charest et de Clermont ne souffre pas la comparaison avec le nombre de citoyen qui ont lu ou entendu le prétendu scoop $^{4}$." « D’autre part qu’ont à répliquer Maurice Ratelle et Russel Bouchard, les deux scientifiques sur lesquels s'appuie le scoop de RadioCanada? Ne se doivent-ils pas de répondre à leurs pairs qui les ont remis en question dans les médias du Québec?" "

\footnotetext{
2. Idem, 545.

3. Voir Recherches amérindiennes au Québec, 27,2 (1997): 92-93.

4. Voir Recherches amérindiennes au Québec, 26,2 (1996): 82.

5. Idem, 82.
} 
Ainsi, loin de m'attaquer à ces historiens, je leur rappelais leur rôle de répliquer à des pairs qui les avaient critiqués publiquement. Ce qu'ils n'avaient pas fait jusque-là. Seul l'un d'entre eux le fera et $R A Q$ publiera son texte. Le titre de ma chronique, percutant ou amusant, utilisait les mêmes armes que le journaliste avec son scoop. Je m'attaquais essentiellement à ce prétendu scoop qui consistait, à mon avis, en une fuite calculée servant à faire de la désinformation aidant l'État dans sa négociation avec des Autochtones. Je n'ai pas attaqué ni critiqué les historiens, mais je leur ai simplement demandé de répondre à deux experts de la question. Alain Beaulieu ne semble pas avoir bien compris le sens de ma chronique.

Alain Beaulieu a tout à fait raison de faire remarquer que le caractère délicat de ce problème découle des critères parfois arbitraires du gouvernement fédéral qui rendent acceptable ou non une revendication de droit ancestral. L'intérêt qu'ont les Autochtones à démontrer la continuité et l'exclusivité de l'occupation du territoire peut sans doute ne pas favoriser l'objectivité en histoire. Mais il serait un peu naïf de croire que des avocats, des historiens ou des anthropologues n'auront jamais à travailler pour une cause. Bien que cela puisse nuire à la vérité historique, il importe de rappeler que les droits des uns et des autres ont tout intérêt à être soutenus par des experts. Hors de l'université, les historiens ou les anthropologues font souvent face à ce problème. Et, dans la vraie vie, le problème du droit des gens est tout aussi important que l'absolue vérité historique.

Par ailleurs, Alain Beaulieu a également raison de critiquer Rémi Savard d'avoir qualifié Denis Vaugeois de «raciste» dans un compte rendu de son livre publié par $R A Q$. La revue aurait dû demander à l'auteur du compte rendu de retirer cette accusation. 